\title{
Sustainable Separation of Paraffin Wax by Span 80 Combined with Switchable Water
}

Xin Lv, ${ }^{a}$ Xiaojiang Li, ${ }^{b}$ Yang Ge,${ }^{a}$ Qingping Li, ${ }^{a}$ and Hongsheng Lu, $,{ }^{*} a, b$

${ }^{a}$ State Key Laboratory of Natural Gas Hydrates, Beijing, 100028, P. R. China

${ }^{b}$ College of Chemistry and Chemical Engineering, Southwest Petroleum University, Chengdu 610500, P. R. China

*Corresponding author:

Email: HongshengLu( hshlu@163.com).

Fax: +86-28-83037330; Tel: +86-28-83037330.

College of Chemistry and Chemical Engineering, Southwest Petroleum University, Chengdu 610500, P. R. China. 


\section{Micrographs of the system consisted of Span 80 and TMHDA solution}

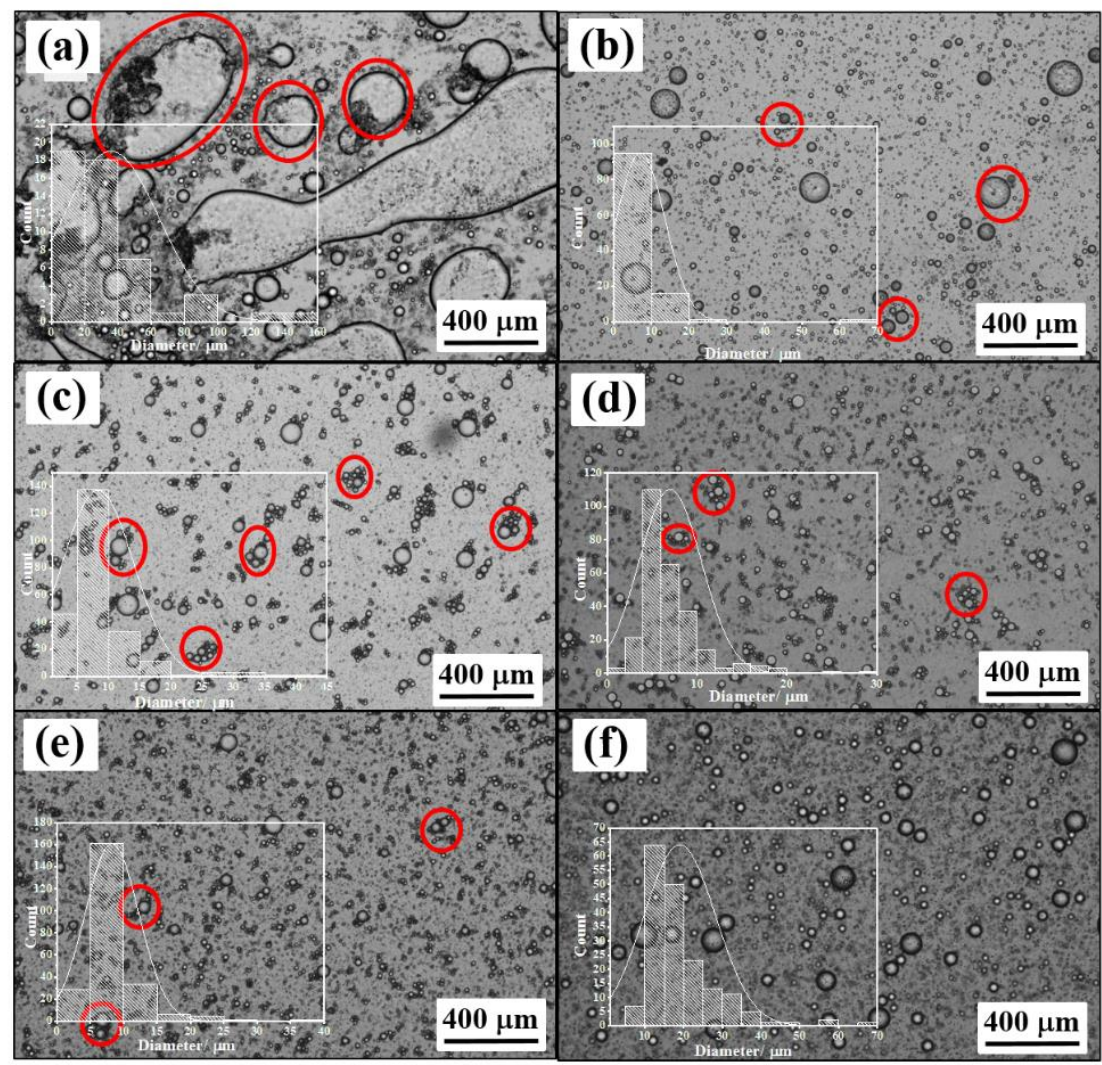

Fig. S1. Micrographs of the system consisted of Span 80 and TMHDA solution with various concentration. (a) $0 \mathrm{wt} \%$; (b) $1 \mathrm{wt} \%$; (c) $3 \mathrm{wt} \%$; (d) $5 \mathrm{wt} \%$; (e) $7 \mathrm{wt} \%$; (f) $9 \mathrm{wt} \%$.

\section{Surface tension of the system consisted of Span 80 and TMHDA solution}

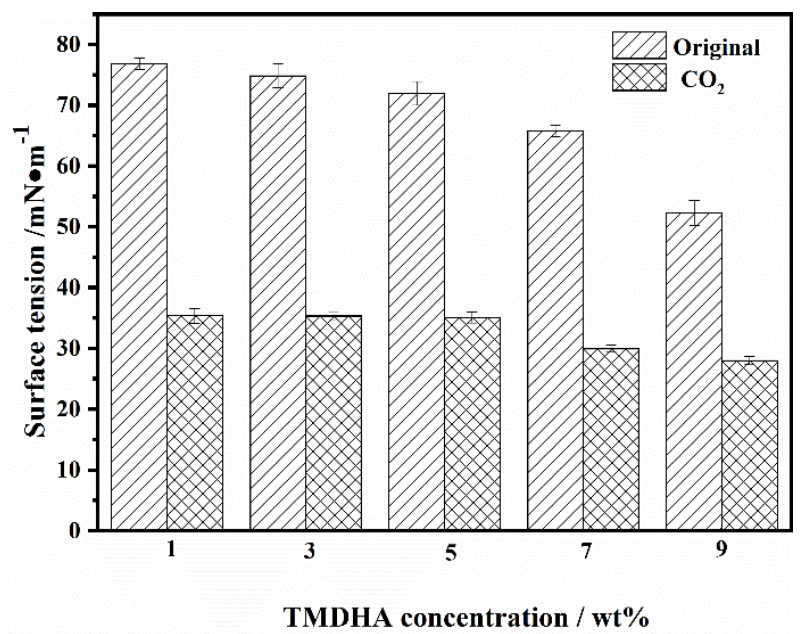

Fig. S2. Surface tension of the system consisted of Span 80 and TMHDA solution with various concentration after treated with $\mathrm{CO}_{2}$.

\section{Photograph of the emulsified paraffin wax with various TMHDA content.}




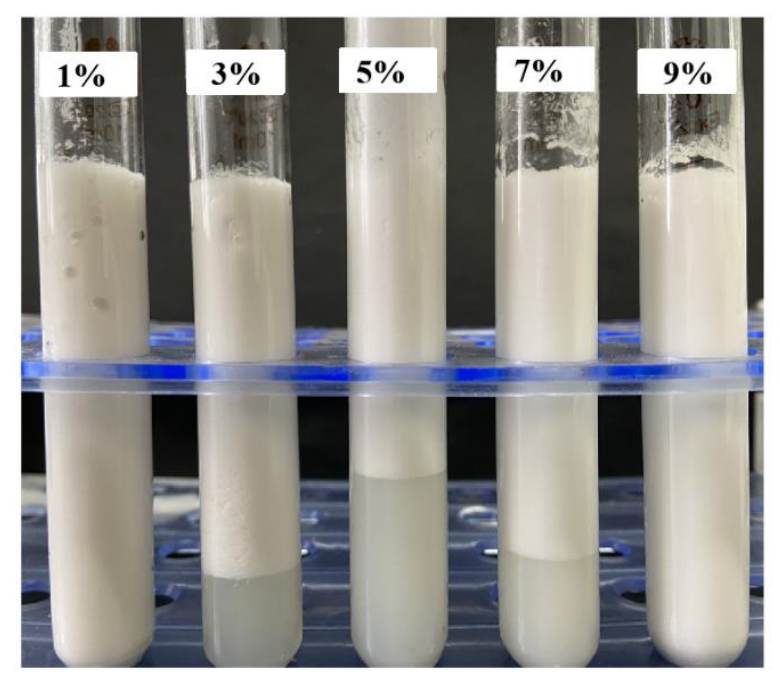

Fig. S3. Photographs of the emulsified paraffin wax with various TMHDA contents.

\section{Photograph of the emulsified paraffin wax with various paraffin wax content}

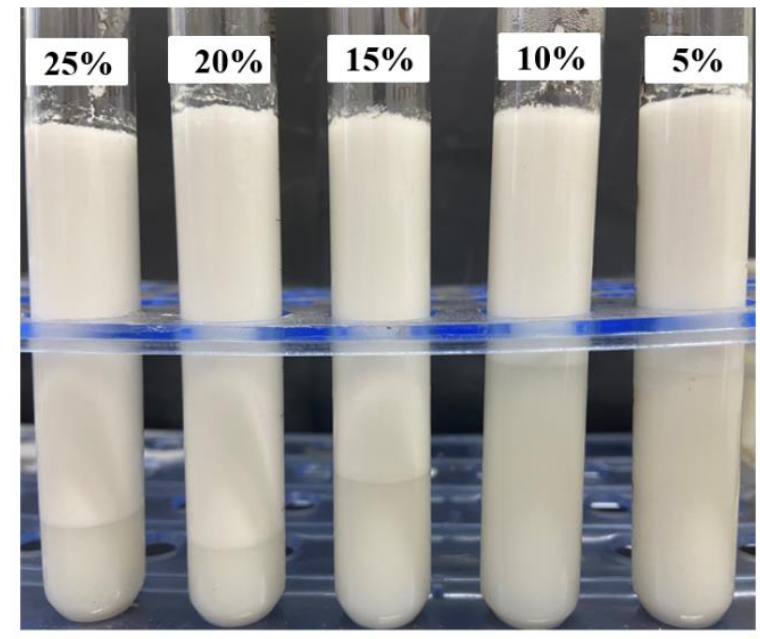

Fig. S4. Photograph of the emulsified paraffin wax with various paraffin wax content.

\section{Photograph of the emulsified paraffin wax with various Span 80 content}

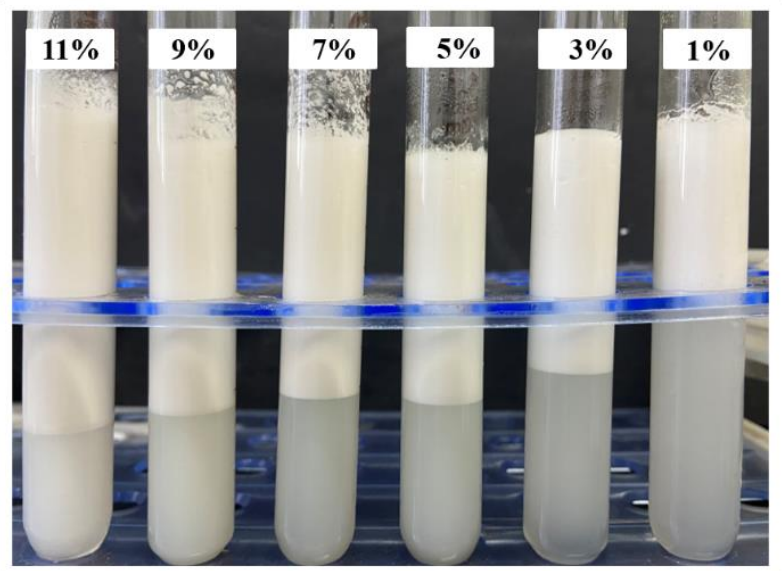


Fig. S5. Photograph of the emulsified paraffin wax with various Span 80 content.

\section{DSC scans of paraffin wax (a) and emulsified paraffin wax}
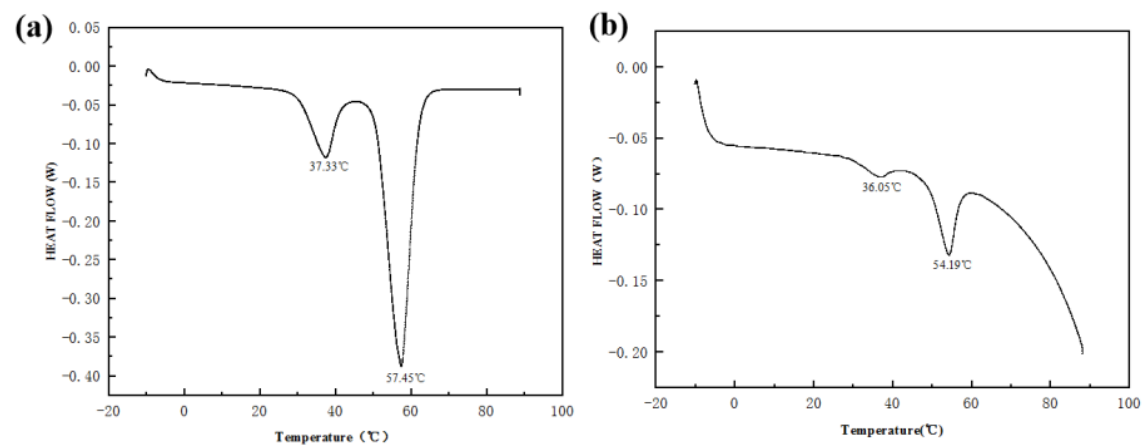

Fig. S6. DSC scans of paraffin wax (a) and emulsified paraffin wax (b).

The melting point of paraffin wax was measured by the DSC curve, where the peak apex temperature was treated as the melting point of paraffin wax. The melting point $37.33{ }^{\circ} \mathrm{C}$ and $57.45{ }^{\circ} \mathrm{C}$ of paraffin wax were also reduced to $36.05{ }^{\circ} \mathrm{C}$ and $54.19{ }^{\circ} \mathrm{C}$ respectively.

\section{FT-IR spectroscopy of paraffin wax and recovered paraffin wax}

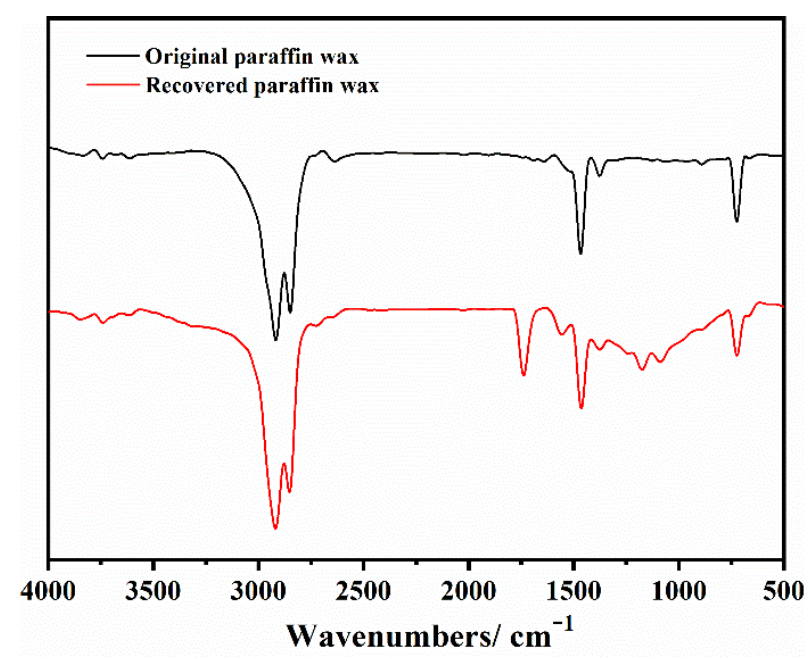

Fig. S7. FT-IR spectroscopy of paraffin wax and recovered paraffin wax.

The FT-IR spectroscopy of original paraffin wax is similar to the recovered paraffin wax. But there are the new peak at 1734,1168 and $1080 \mathrm{~cm}^{-1}$, which is ascribe to the residual Span 80 . 
8. Photographs of the emulsification and separation behavior

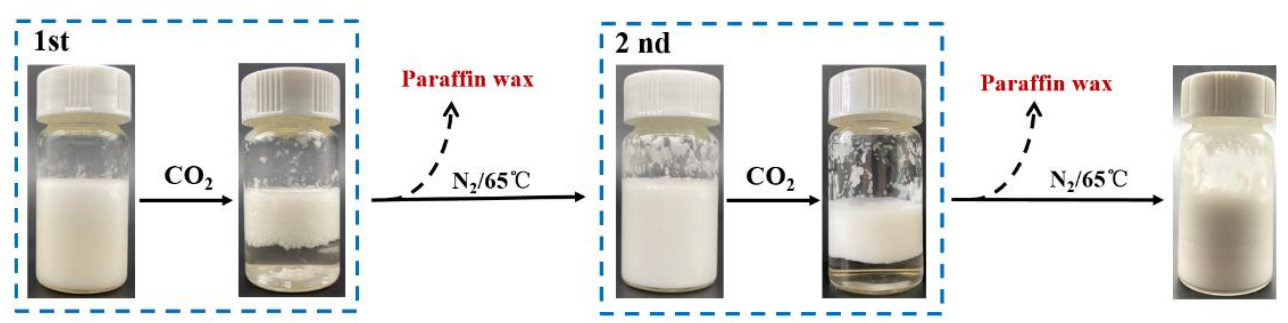

Fig. S8. Photographs of the emulsification and separation behavior for paraffin wax based on TMHDA. 